\section{Parent-offspring interactions determine time and place of first ingestion of solid food by wild rat pups*}

\author{
BENNETT G. GALEF, JR., and MERTICE M. CLARK \\ McMaster University, Hamilton, Ont, Canada
}

Wild rat pups maintained on ad lib food in a large enclosure with feeding sites not visible from nesting areas ingest their first samples of solid food at the same time and in the same place as adults of their colony. Blind pups maintained under the same conditions do not take initial meals of solid food in the presence of adults.

As the lactation of a recently parturate female rat gradually wanes, her young must emerge from the nest site and learn their way about an unfamiliar and potentially hostile environment in order to locate needed nutrients. Scott (1958) has stated that wijd rat pups in the process of weaning "have to go out and find their own food once the nursing period is over [p. 117]." However, in recent papers (Galef, 1971; Galef \& Clark, 1971, in press), data were presented indicating the importance of interactions between adult and juvenile wild rats in the pups' choice of diet for first ingestion. When colonies of adult wild rats, established in $6 \times 3 \mathrm{ft}$ enclosures on a $3 \mathrm{~h} /$ day feeding schedule, were trained to eat a nonpreferred diet and avoid a preferred diet, as a result of the latters' previous association with poison (lithium choride), pups born to colony members ate onily the diet the adults of their colony were eating and completely avoided ingesting the alternative normally preferred diet for the 10 days they were left with adult colony members. After transfer to individual enclosures, these pups continued to avoid ingesting the normally preferred diet for as long as 1 month. These and subsequent observations were interpreted as demonstrating the existence of a three-stage process in which pups first followed adults to food and initiated feeding on the djet the adults were eating, then learned cues associated with that diet, and thereafter avoided alternative diets as a result of their inherent neophobia. The phenomena described in Galef and Clark could not be readily generalized to the behavior of wild rats in natural environments for two reasons. First, the animals in

*The research reported here was supported by National Research Council of Canada Grant APA-0307 and a McMaster University Research Board grant to the senior authoz. We would like to thank Miss Patricia Greene for her assistance in the collection and amadysis of data, and Mr. Jaseph Turkel for his enucleations. our earlier experiments were confined in abnormally small enclosures with feeding sites readily visible from nest. entrances. Second, and more important, in order to facilitate observation, the animals in our previous studies had food available to them for only $3 \mathrm{~h} / \mathrm{day}$. The presence of food in the enclosure for only a relatively brief period during the day forced the pups to eat solid food at the same time that the adults of their colony were actively feeding, perhaps artificially enhancing parent-offspring interactions. It is possible, especially in light of observed instances of aggression directed toward pups by adults in the vicinity of the food bowl, sites of all five litters in Experiments 1 and 2.
(Galef \& Clark, 1971) that pups would, if given the opportunity, choose to feed at a time when no adults were feeding and would thus avoid interaction with them. The present observations were undertaken in order to examine the conditions under which wild rat pups first ingested solid food while living in moderate sized enclosures with food constantiy available at a distance of from 10 to $12 \mathrm{ft}$ from the nest site. EXPERIMENT 1

Subjects

The Ss were a colony of two male and four female fourth-generation laboratory-bred wild rats and three litters born to the colony (reduced to three pups each). Pups were marked by tail clipping so as to be individually identifiable on closed-circuit television.

\section{Method}

The colony was established in the enclosure shown in Fig. 1. Food (powdered Purina rat chow placed in two ceramic food bowls, $5^{3 / 4}$ in. in diam, $21 / 2$ in. deep, located approximately 18 in. apart) and water were available ad lib, and the enclosure was constantly illuminated by overhead fluorescent lights. The food bowls were placed behind the partition shown in Fig. 1 in such a position that they could not be seen by an animal

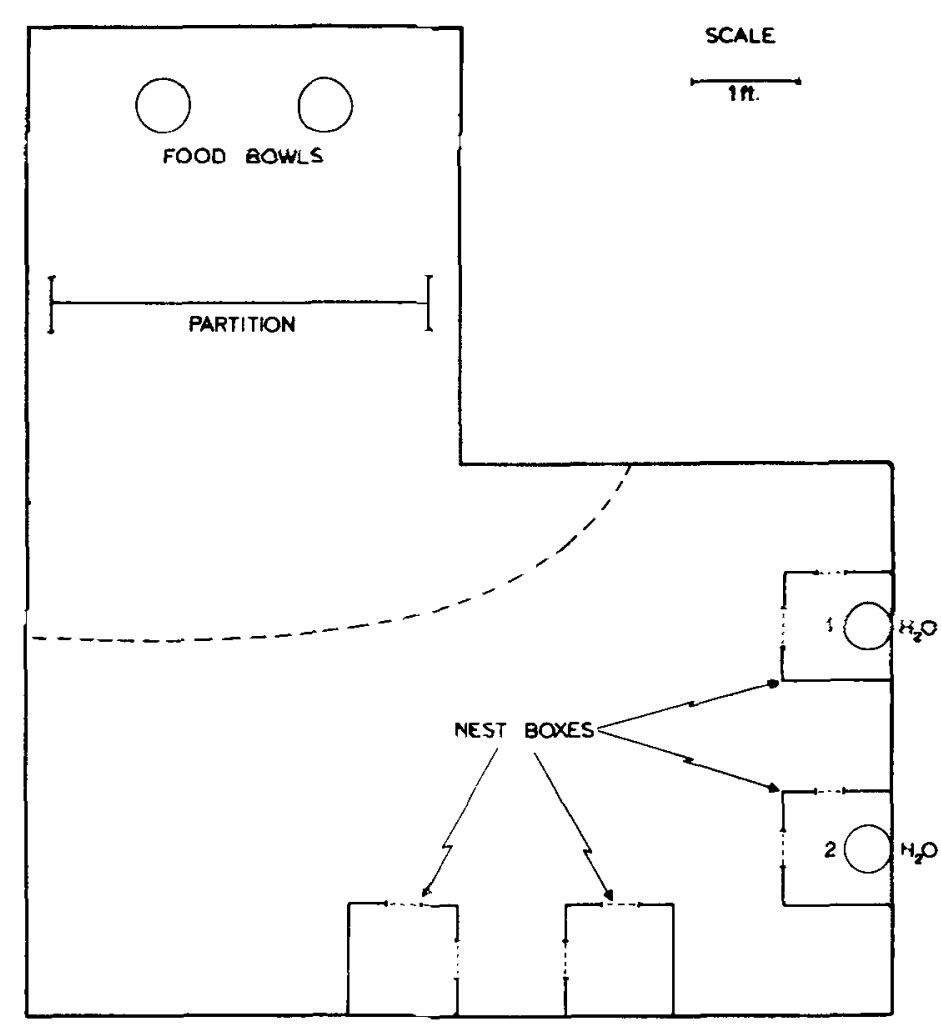

Fig. 1. Enclosure for wild rat colony. The area above the dotted line was continuously monitored. The numerais 1 and 2 indicate the location of the rest 
until it passed the partition. The colony was left undisturbed throughout the experimental period

The activity of colony members in the area above the dotted line in Fig. 1 was recorded $24 \mathrm{~h} /$ day, using a Sony EV-320 TLV time-lapse videotape recorder $(1 / 60 \mathrm{sec} / \mathrm{sec})$. The tapes were viewed several times by two independent Os to determine the first instance of feeding by each pup (there was complete agreement between Os as to first occurrence of feeding for all nine pups) and to observe parent-offspring interactions occurring at the time of first feedings. Determinations were also made of the total time adults spent feeding each day.

\section{Results and Discussion}

All nine of the pups in the present experiment ingested their first meal of solid food while an adult was feeding, and all nine fed at the same food bowl as that adult, none at the alternative bowl 18 in. distant. Of course, the possibility exists that adult colony members were feeding constantly throughout the day and that the observed presence of feeding adults at the time of each pup's first meal is of no importance. However, observation of the adults' feeding behavior during the hour in which each pup first ate showed that, on the average, adults were eating only $39 \%$ of the time during that hour. Similarly, on the average, adults fed during only $31 \%$ of the time during the night hours (11 p.m. to 9 a.m.) on which each pup first ate. (Data were considered for the hours from 11 p.m. to 9 a.m. only because the rats fed infrequently during the hours of activity in adjacent laboratories and inclusion of data from these hours would have exaggerated the improbability of occurrence of a pup's first ingestion of food in the presence of an adult.) The probability of all nine pups feeding for the first time in the presence of a feeding adult by chance under the conditions reported here is $<.001$.

Observation of each pup's first feeding revealed that the pups never followed an adult from the area of the nest box to the food bowl. In every case, a pup approached an adult already feeding at a food bowl for its first meal of solid food.

The present observations support the hypothesis that wild rat pups are influenced in their selection of a site for first ingestion of food by the feeding behavior of the adults of their colony. First, all nine pups ate their first meal of solid food in the presence of an adult $(p<.001)$ under ad lib feeding conditions and, second, each of the nine pups took its first meal at the same bowl as the adult it approached $(p<.01)$.

The fact that the rat pups in the present experiment do not actually follow an adult to food, but rather approach a feeding adult and begin to eat at the location at which he is eating, does not support the suggestion of Galef \& Clark (1971) that "trailing" of adult wild rats by pups (Calhoun, 1962 ) is responsible for the observed phenomenon. To the contrary, the present observations indicate that a tendency of pups to approach adults when they are at a distance from the nest site and to begin eating in their vicinity (Galef, 1971) is the mechanism by which the parent-offspring interaction proceeds in the present situation. Finally, the present observations indicate that the phenomena described by Galef \& Clark (1971) are not restricted to small enclosures or to animals on limited feeding schedules and, therefore, are probably generalizable to the behavior of colonies in the wild. EXPERIMENT 2

The experimental situation described in Experiment 1 provides the opportunity to investigate directly the role of various sensory modalities in mediating the observed interaction between adults and young. Results of a previous study have indicated that visual cues are important in inducing wild rat pups to eat in close proximity to one another (Galef \& Clark, 1971). In this earlier experiment, the distribution of feeding site selections by pairs of wild rat pups was shown to be essentially random when pairs of pups were separated by opaque barriers but highly correlated when the pairs were separated by transparent barriers. The data were interpreted as demonstrating the sufficiency of visual cues in mediating the interaction between pups in feeding site selection. Further, the fact that the pups in Experiment 1 were observed to approach adults directly from a distance at the time when they first ingested solid food suggests the importance of visual cues in parent-offspring interaction. The present experiment was designed to investigate directly the role of visual cues in mediating the influence of adults on pups' selection of site for first ingestion of solid food.

Subjects

The Ss were two additional litters of pups (reduced to three pups/litter, marked by tail clipping, and enucleated at 9 days of age) born to the colony described in the Subject section of Experiment 1 .

\section{Method}

The method was identical to that of Experiment 1.

Results and Discussion

Blind pups differ markedly from sighted ones in the conditions under which they first feed. Whereas all nine sighted pups initially fed with adults, only one of six blind pups did so. The five blind pups that initially ate alone appeared to find the food bowl by chance, bumping into it in the course of their explorations about the enclosure.

The one blind pup which initially ate with an adult showed very close trailing of that adult, following the adult from the nesting area directly to the food bowl, with its nose immediately adjacent to the base of the adult's tail. When the adult stopped to eat, the pup crawled under the adult to its head, hopped into the food bowl, and began to feed. Three other blind pups similarly trailed adults to food bowls from the nesting area, but returned to the nesting area without feeding when the adult each was trailing stopped to eat. No sighted pups were observed to trail in this fashion. These observations suggest that nonvisual cues could serve as the basis of parent-offspring interactions in feeding-site selection. However, the data indicate that visual cues are necessary for adults to influence reliably pups' choice of time and place of first ingestion of solid food.

\section{REFERENCES}

CALHOUN, J. B. The ecology and sociology of the Norway rat. Bethesda, Md: U.S. Department of Health, Education and Walfare, 1962.

GALEF, B. G., JR. Social effects in the weaning of domestic rat pups. Journal of Comparative \& Physiological Psychology. $1971,75,358-362$

GALEF, B. G., JR \& CLARK, M. M. Social factors in the poison avoidance and feeding behavior of wild and domestic rat pups. Journal of Comparative \& Physiological Psychology, 1971, 75 , 341-359.

GALEF, B. G., JR., \& CLARK, M. M Mother's milk and adult presence: Two factors determining initial dietary selection by weanling rats. Journal of Comparative \& Physiological Psychology. in press.

SCOTT, J. P. Animal behavior. Chicago: University of Chicago Press, 1958. 